\title{
خلامة المنزل
}

كما ظهرت في منائلر مأبر بنى حسن

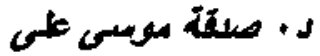

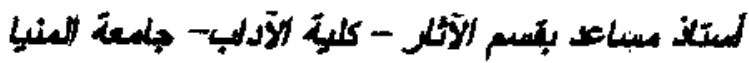

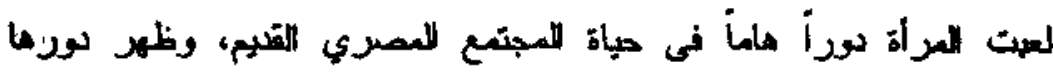

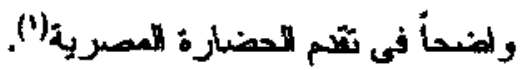

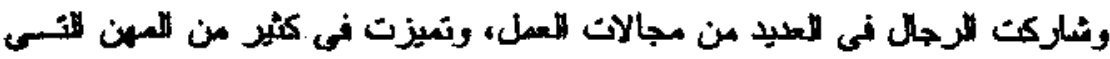

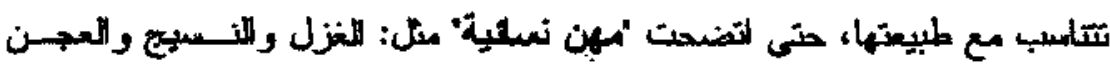

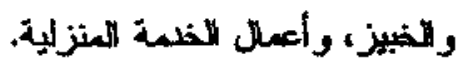

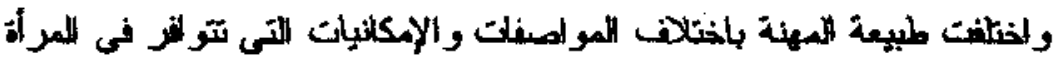
التى تصارسهاء فلأنعاء صاحبات المورامب والعلامات الاجتصاعية كن بلتحقن بمهـن

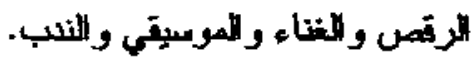

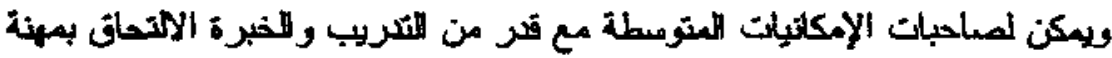
التزل و النعيج مثئز.

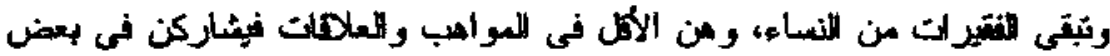

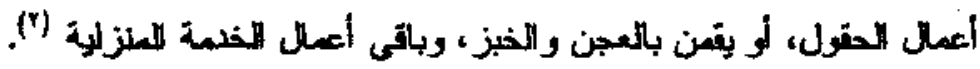

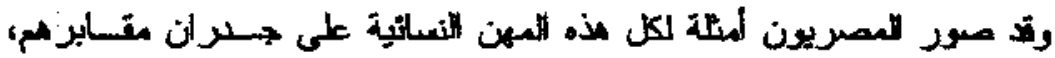

ومنها مناظر خلهمة اللعنزل .

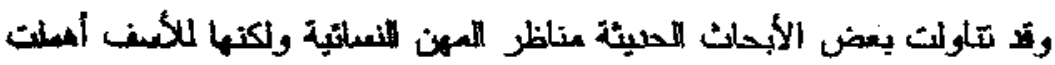

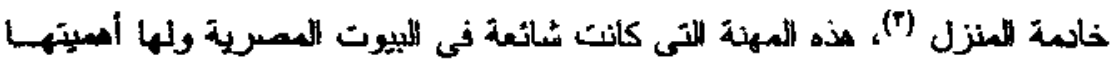

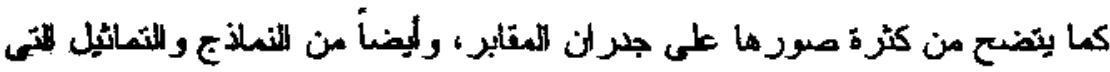




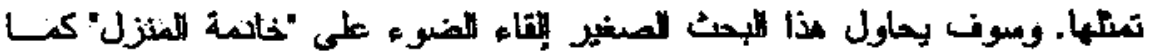

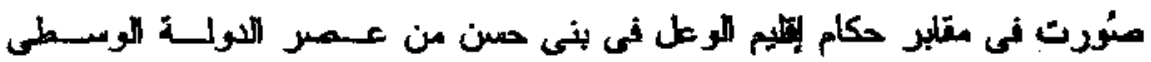

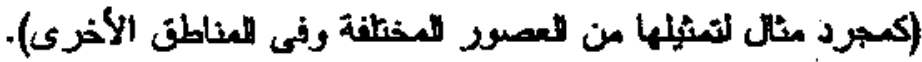

\section{움우}

htt-pr : Maid house - messeger .

(4) نزم نيوبرى)

to[

Q 1

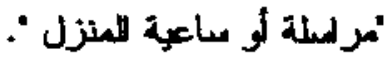

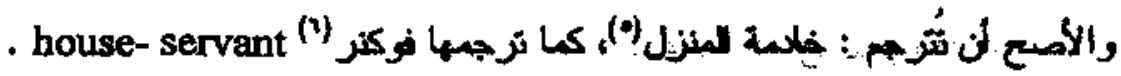

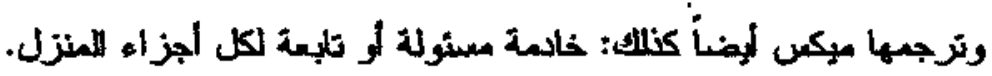

Servante (qui acces a toutes les parties de la maison). (i)

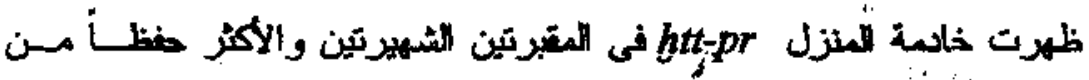

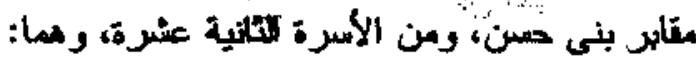

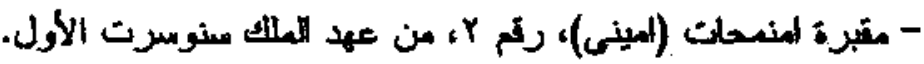

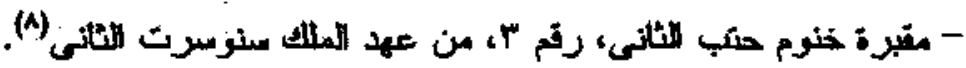

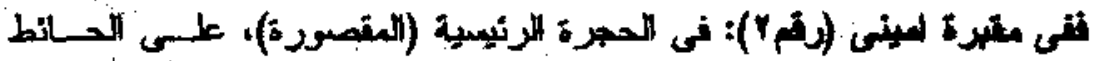

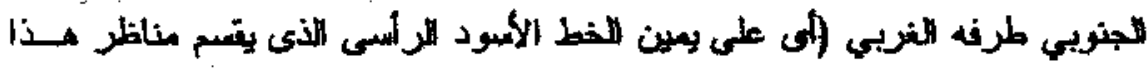

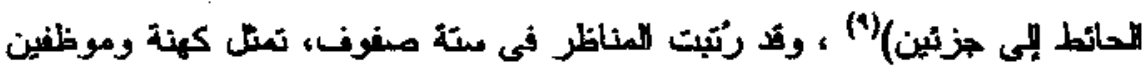

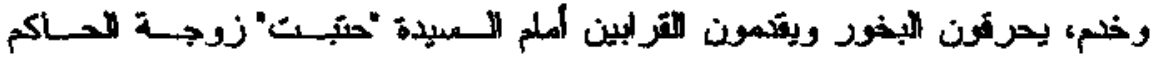

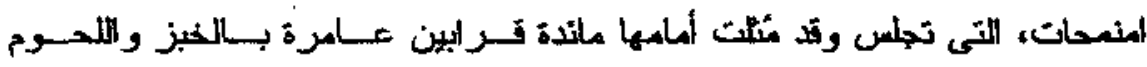

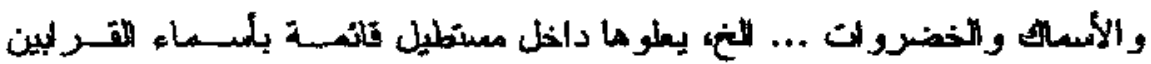
والعطور والادمون و للبخور.

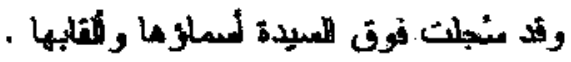




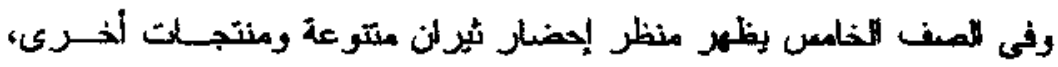

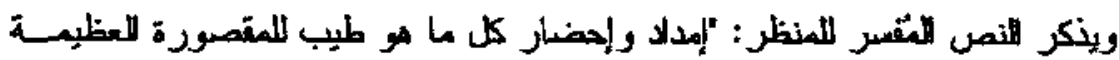

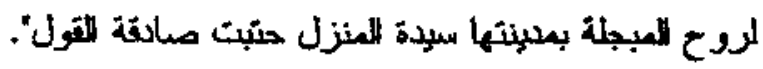

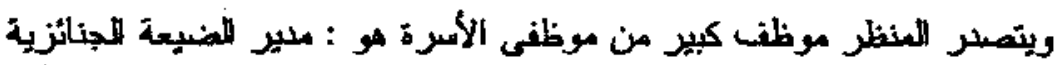

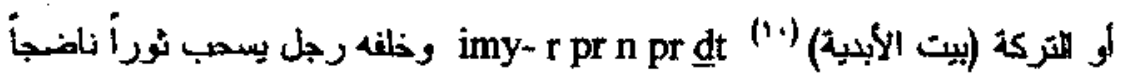

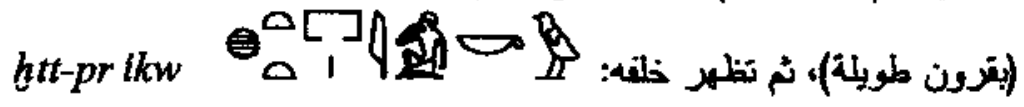

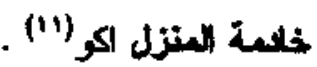

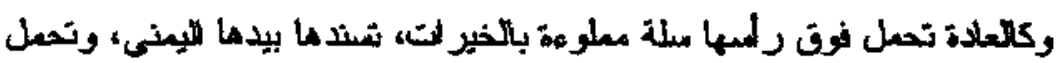

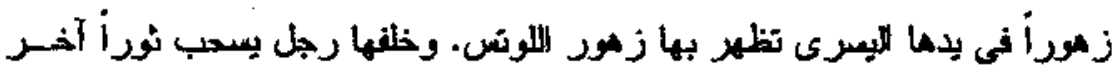

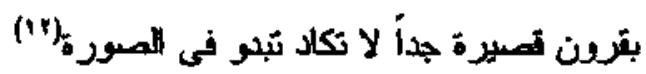
응션

نم نظهر خاصة أخرى

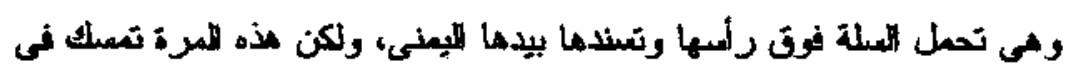

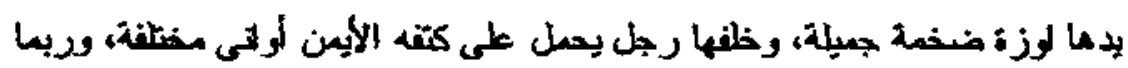
htt-pr hr(w)

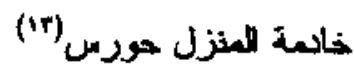

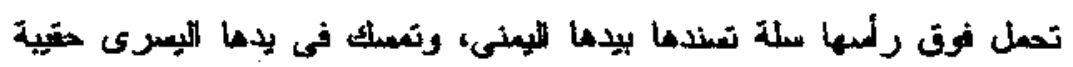

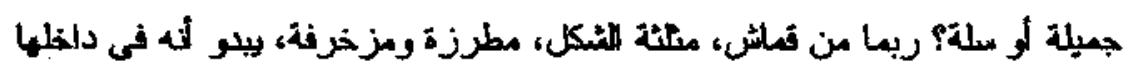

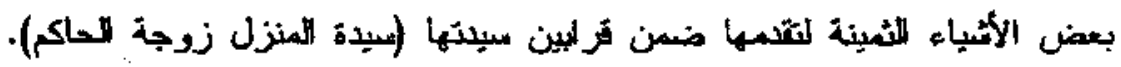

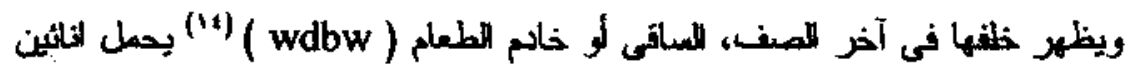
كبيرين. 


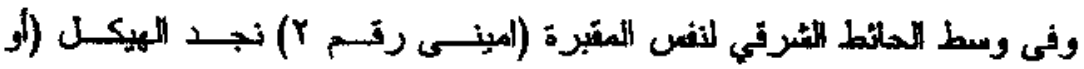

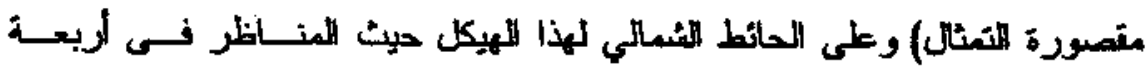

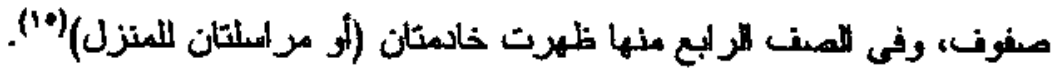

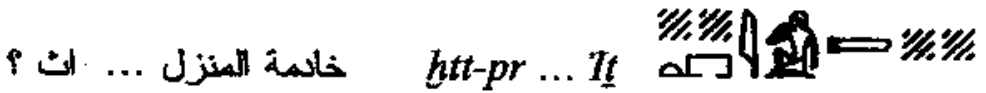

خادمة المنزل امى (iv") htt-pr $\operatorname{lmi}$ ishl تحمل كل مثها علة مملوعة بالخيرات فوت رلمها، وتمعك الأولى فى يهدما

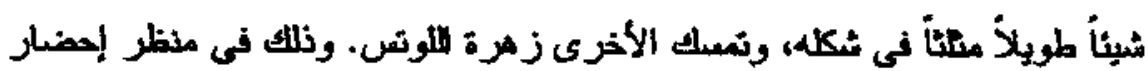

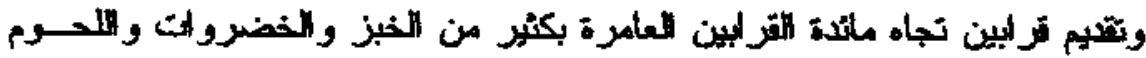

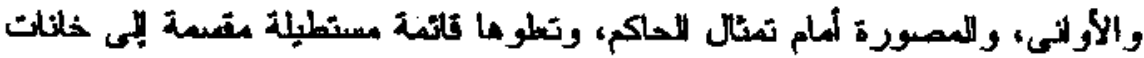

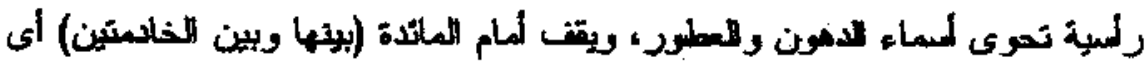

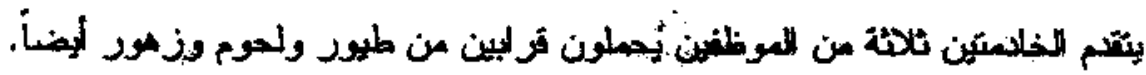

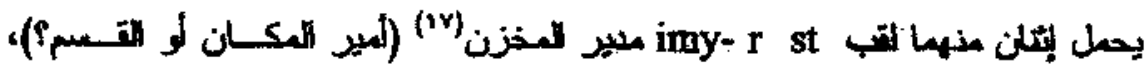
ولأثلث: صائد الميور

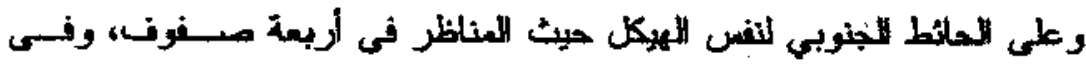

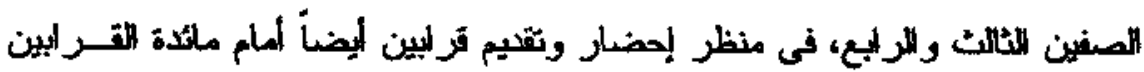

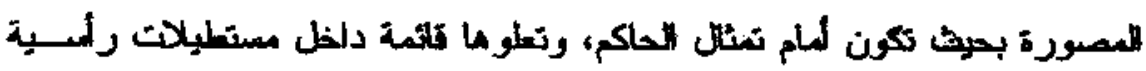

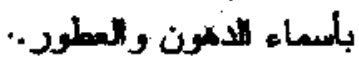
ظهرت خادمتان (19)"

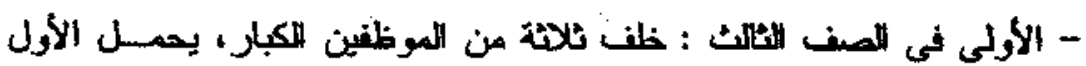

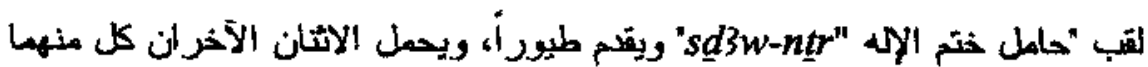

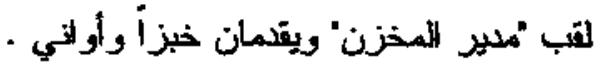


httt-pr ḥkt- hatp ${ }^{(r \cdot)}$

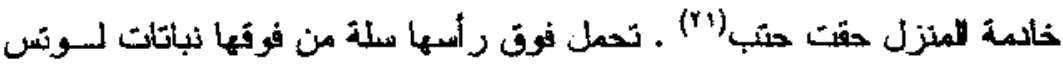

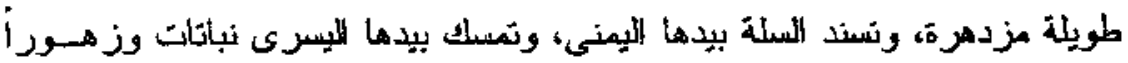
أيضاً .

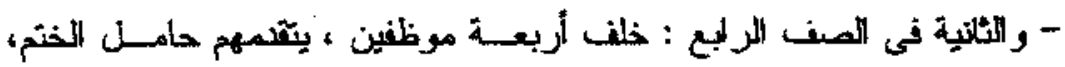

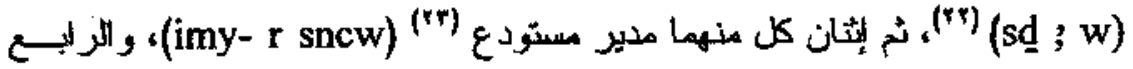

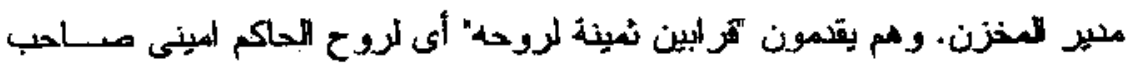

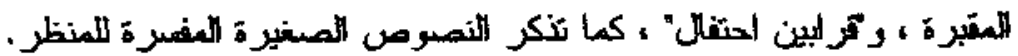
$\operatorname{li}_{0}^{\infty}$ رخهم خامة المنزل مرى

Htt-pr mri (ro)

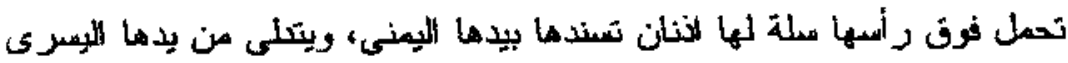
شئ غيز والضح (ربما بقايا حقيية مثنثه).

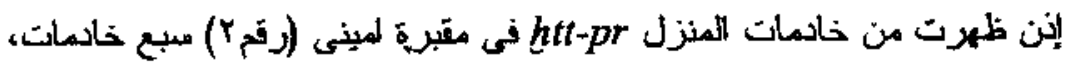

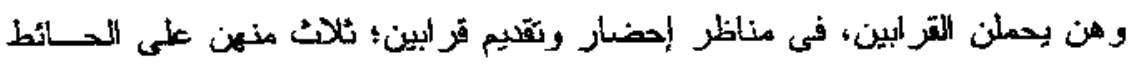

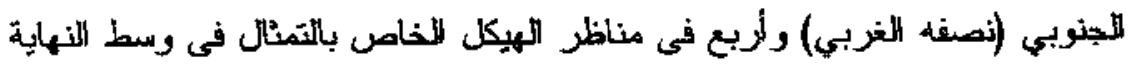
القرقية للمقبرة. 
وفى مقبرة حاكم هنعة خوفو، رئيس التصحراو أت المثرقية ختوم حتب الثـلتي

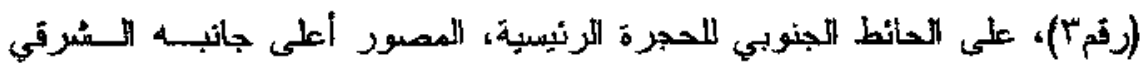

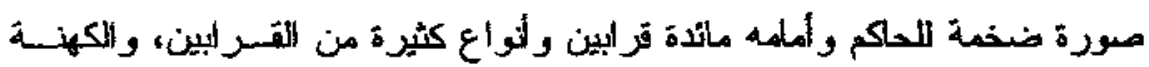

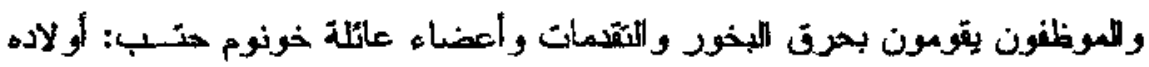

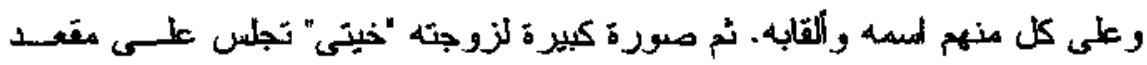

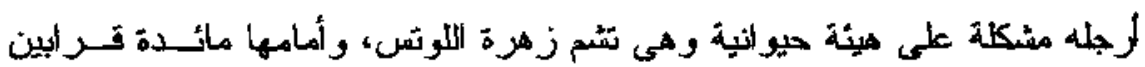

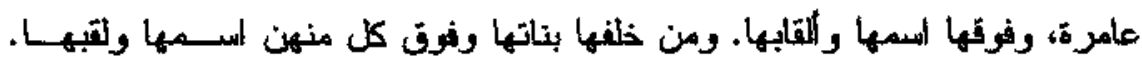
وتحت ذلك مناظز الكهنة والموظفين واللخدم يقدمون القر ابين فى صفوف. وهن.

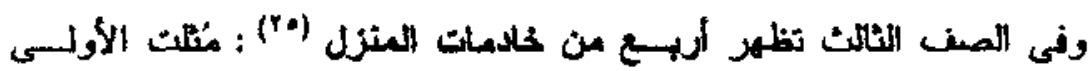

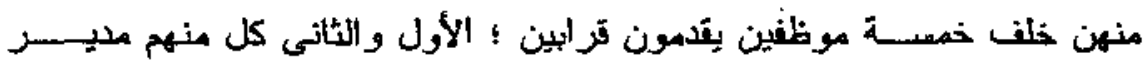

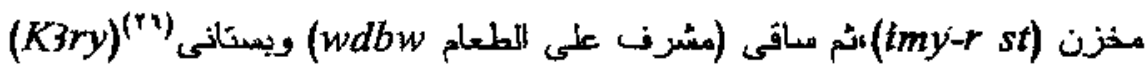

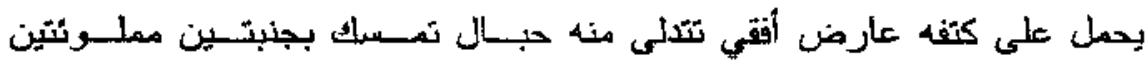
بالخخرورات و الفو أكه، وخلفه مدير مستودع (imy-r

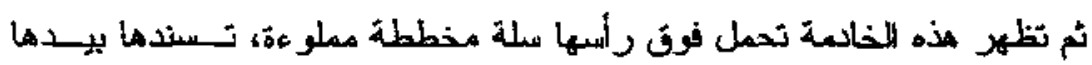

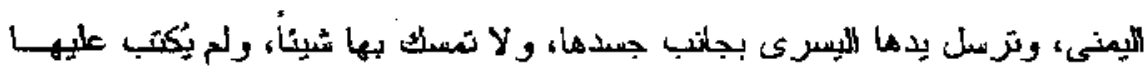

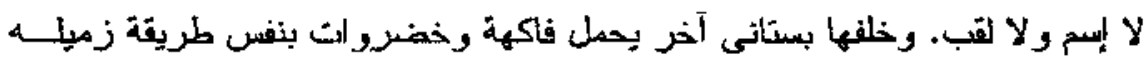
الكابت - علي جنبتين متعلقتين بالحبال المتكلية من ملرفى حامل أفقى فوق كتفه.

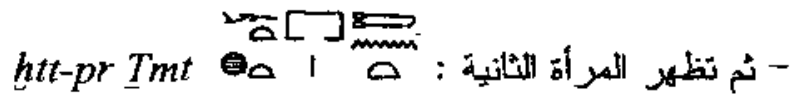

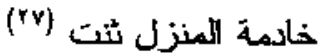
تحعل فون رأسها سلة مخططة ومملو عة - مثل سلة زميلتها لئبابقة- تسندها

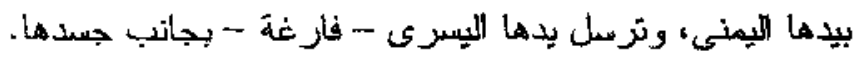




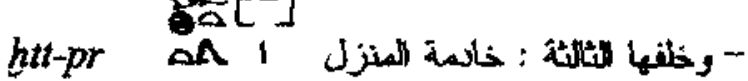

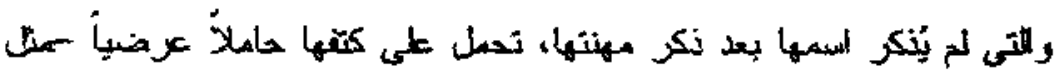

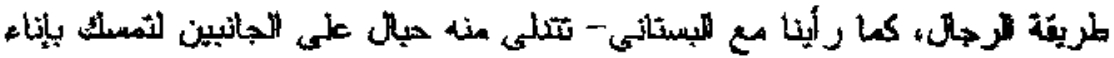

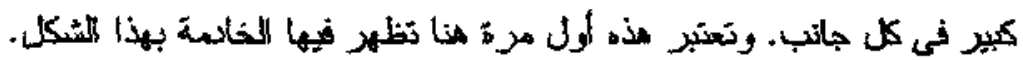

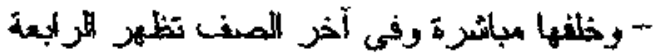

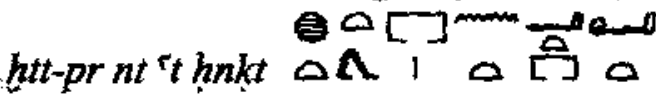

خلامة المبزل بقسم التقز لبين

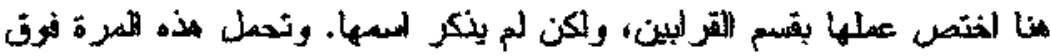

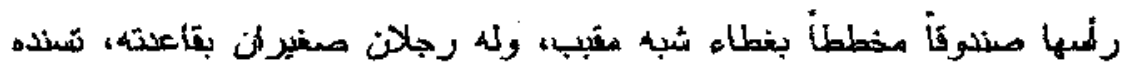

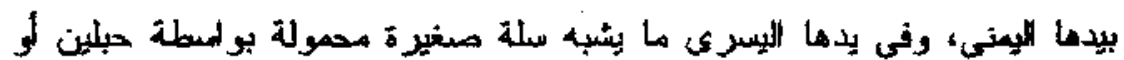
خيطلين، لو ربها إناء مربومنأ بحبل.

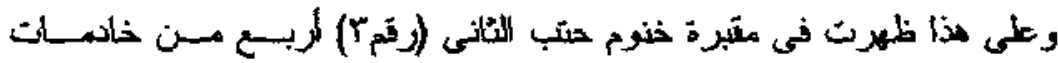

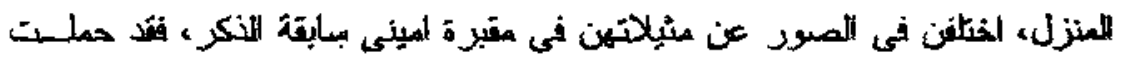

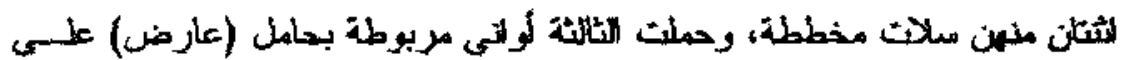

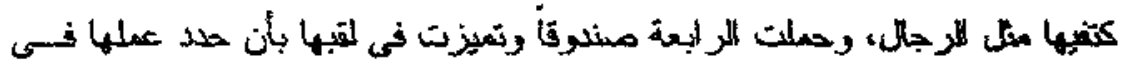

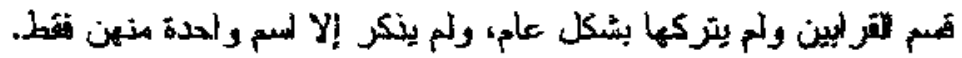

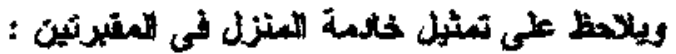

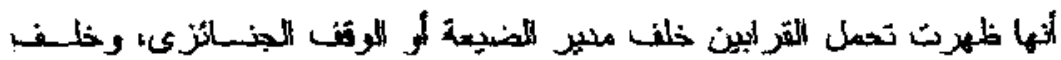

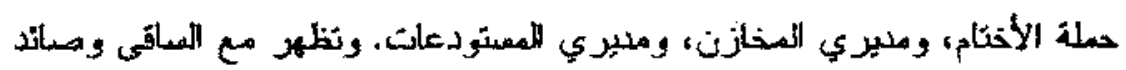
اللطيور واليبستاني وهم يحمرون ويقدمن القرايبين . 


\section{الثراجع والثهامش}

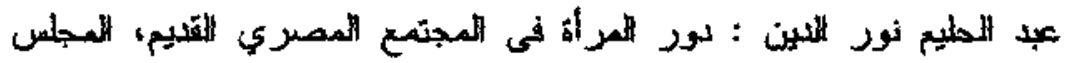

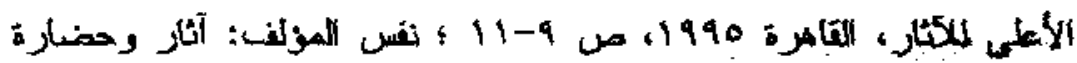

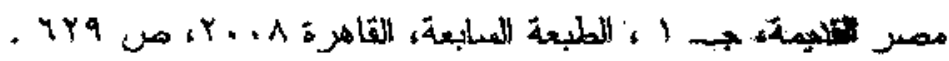

(2) Engy Moh. Yehia El-Kilany, Scenes Bupicting FE Occupations in Ancient Egypt at the Private Tomps Fromet Old Kingdom to the end of the New Kingdom, Tourist Guidence Section for the Degree of Ph. D, Minia University, Faculty of-Tourism \& Hotels, 2007, pp. 1- 2 .

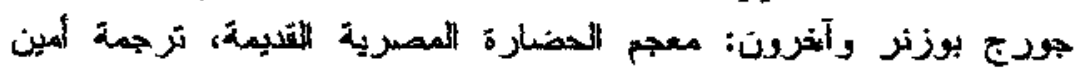

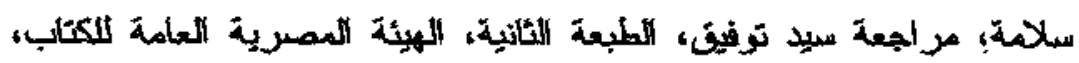

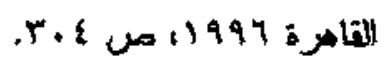

(3) Engy El - Kilany, o.c, pp. 88 ff,

(4) Newberry, P.E., Beni- Hasan, I, London 1898, p. 16.

(5) Wb. III , 344, 12 .

(6) FCD, p. 198.

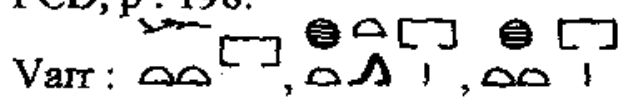

(7) Meeks, Alex. Il, p . $290(78$, 3150).

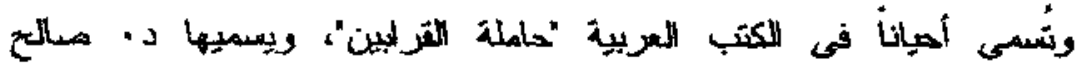

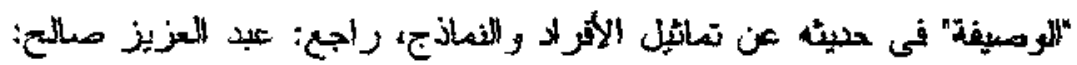

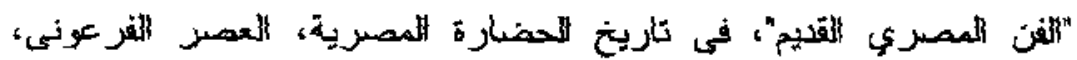

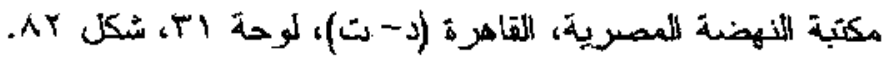


(1) عن تخطيط و عمارة وتأريخ ألمقبرين راجيخ: صنحقة موسى على : الاقليم

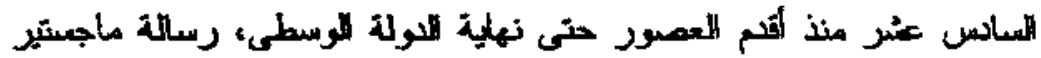

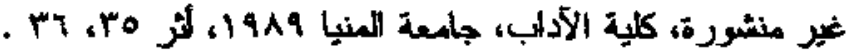

(9) Newberry, o.c. pl. 18.

(10) Gardiner. Eg. Gr., p. 565 ; FCD, p. 89 , 90 ; Ward, Index (1982), p. 24, (No 152).

(11) $\mathrm{PN}, 1,48,9$.

(IV)

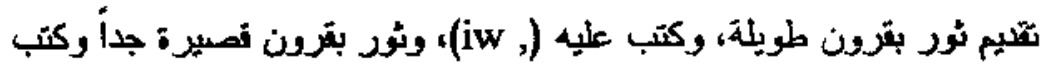
: تعليه (wndw

Newberry, o.c., pl. 18 ; FCD , p. 12 .

(13)PN , I , 245 , 18.

(14)Newberry , o. c . , pl. 18 ; Wb, I, 388, 3 ; Gardiner , AEO, I, p. 43 ; FCD , p. 73 ; Meeks, Alex. I, p. 104 (77. 1104).

(15)Newberry, Beni , - Hasan , I, pl . 19.

(16)PN , I , 25,17 .

(17)FCD , p. 206 ; Meeks , Alex. III, p . 235 (79. 2372).

(18)FCD , p . 66 ; Meeks, Alex. I, p . 95 (77. 1001).

(19) Newberry, o.c., pl . 20 .

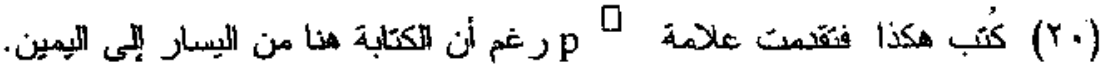
PN , I , 225, 29 . 


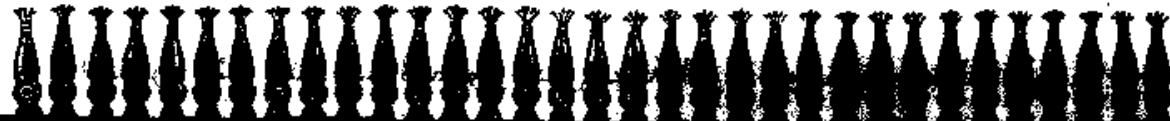 1.}

(1)

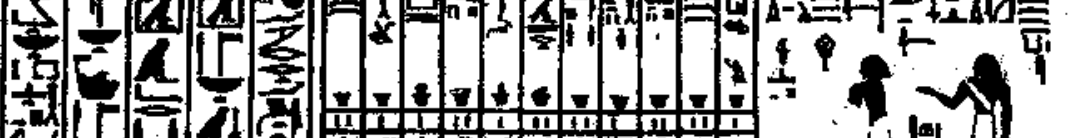

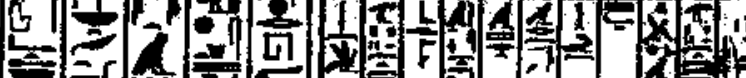

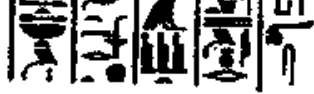

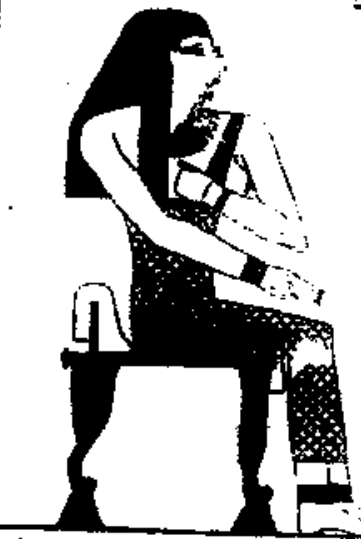

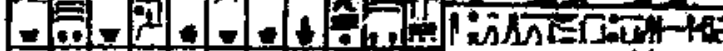
पninitin

is

$\Lambda-n-1$ ह

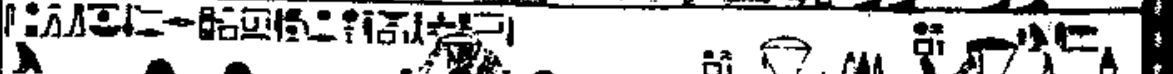

c. Fon

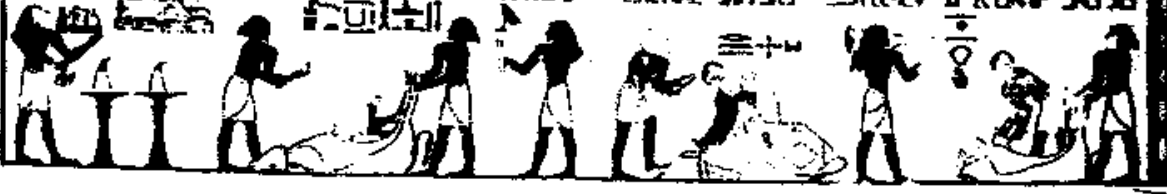
(15.

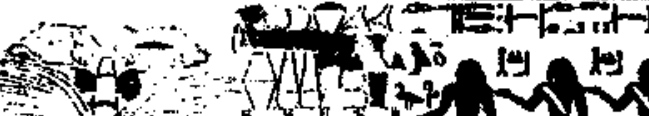
(fin

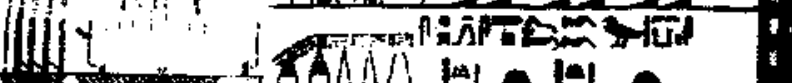

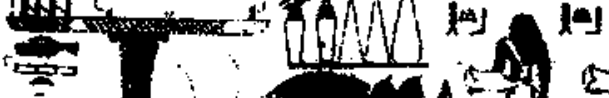

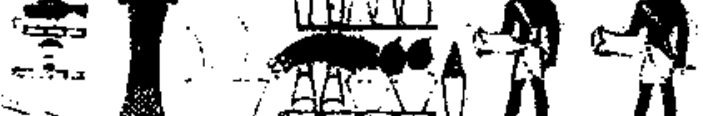




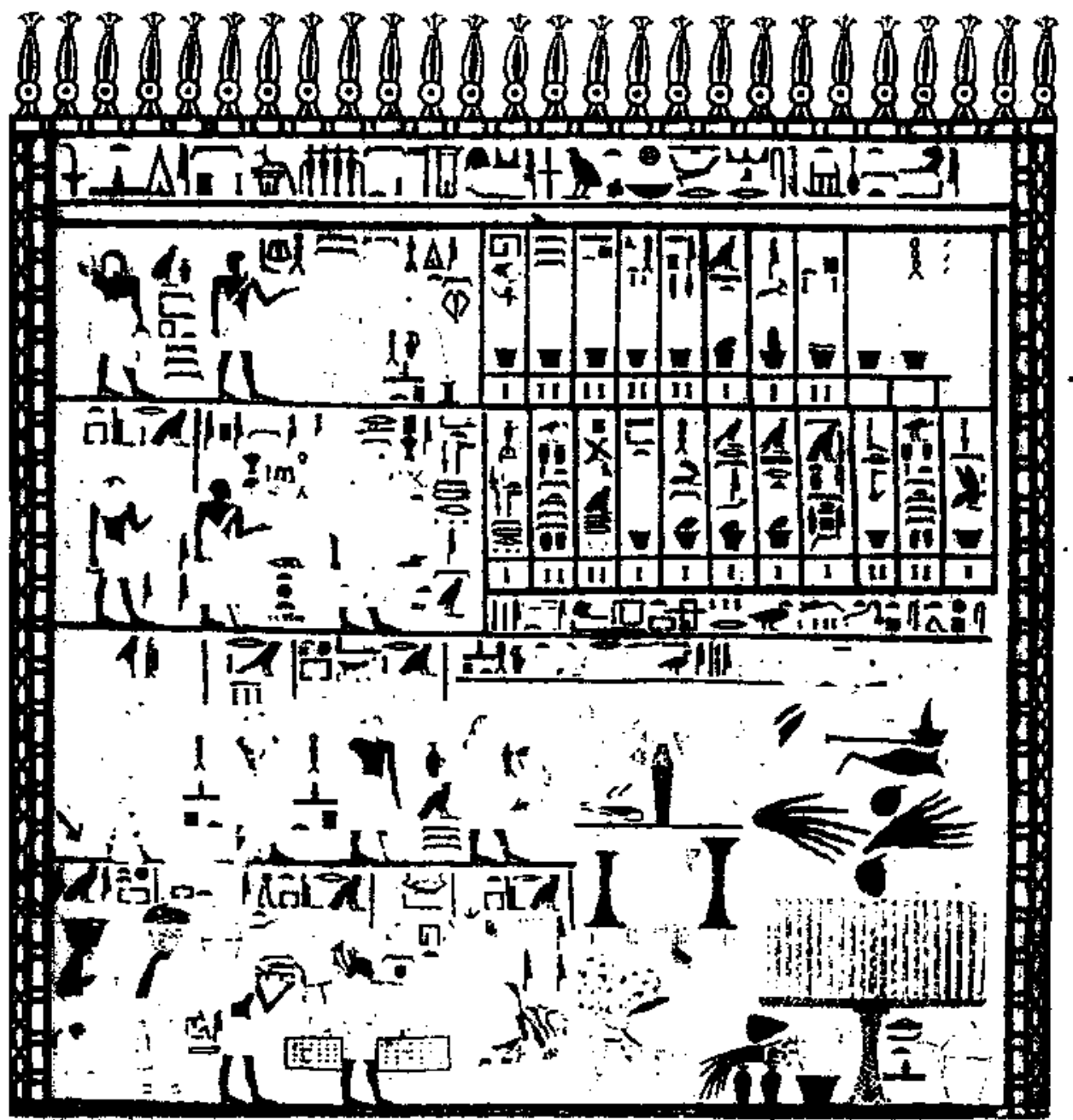

ثكل Y - الحائط الثمالى من لاهيكل فى مقبرة لمينى

(Newberry, BH, I , pl , $19: c$ ) 


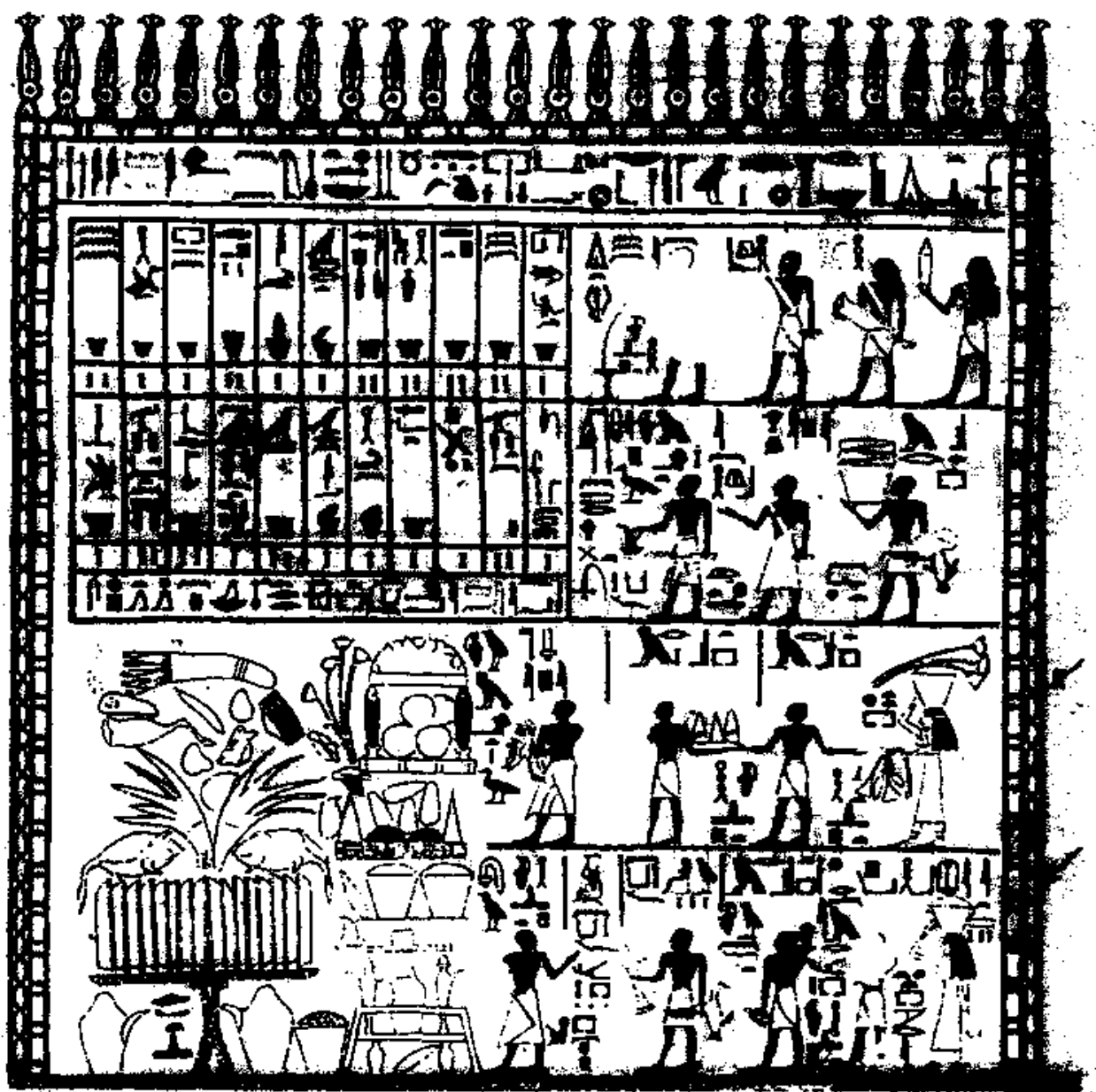

شكل ب- الحائط الجنوبى من اللهيكل فى مقبرة امينى

(Newberry, BH, I, pl, 20 : c) 


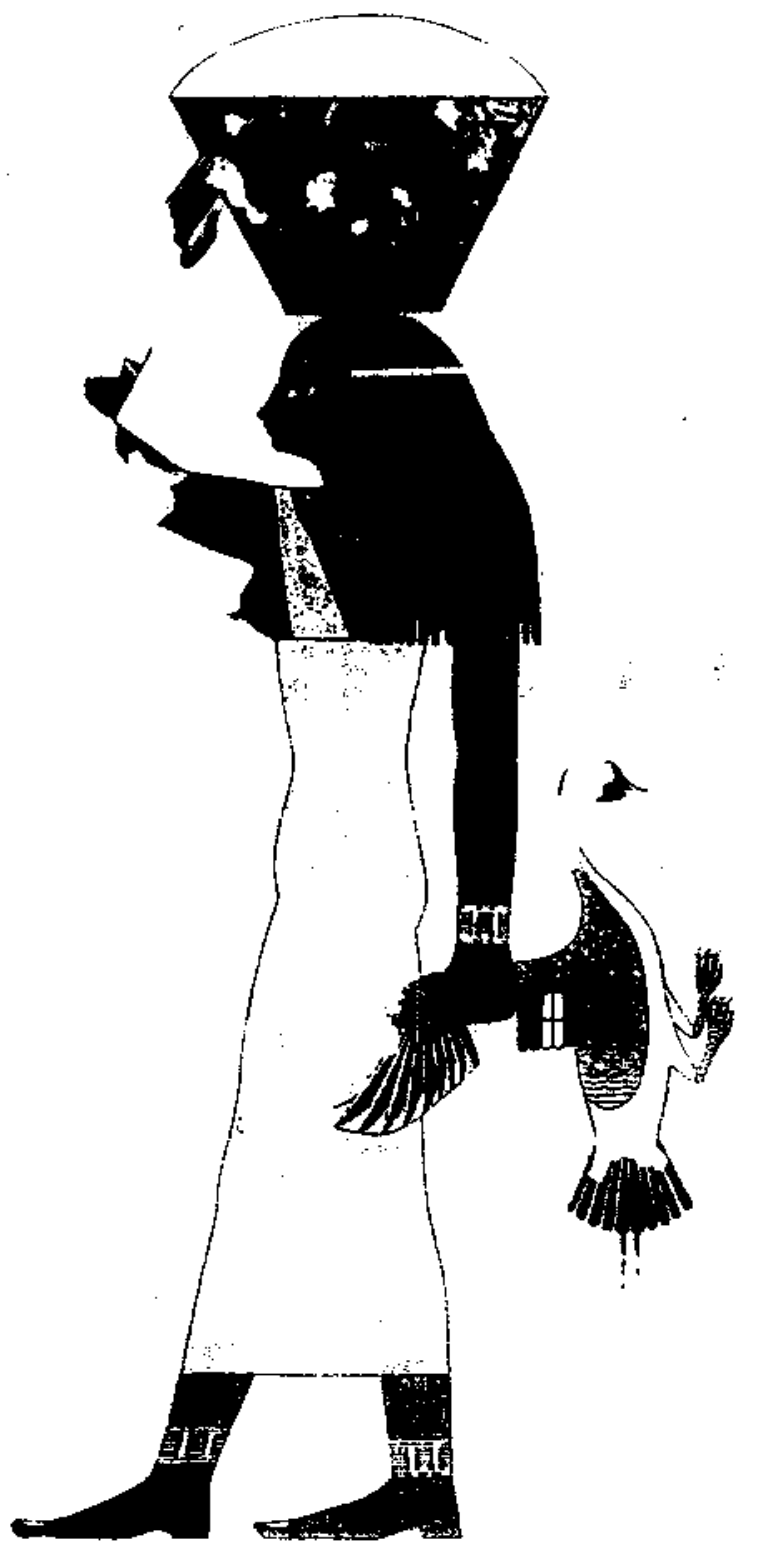

شكل ئ - خادمة المنزل "انبي" هن مقبرة امينى

(Newberry, BH, 1, pl, $10: 5$ (عن) 


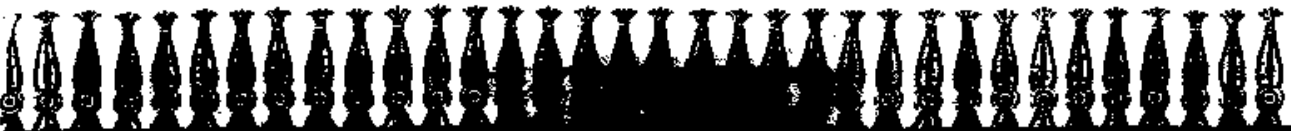

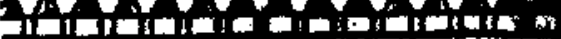
蝶

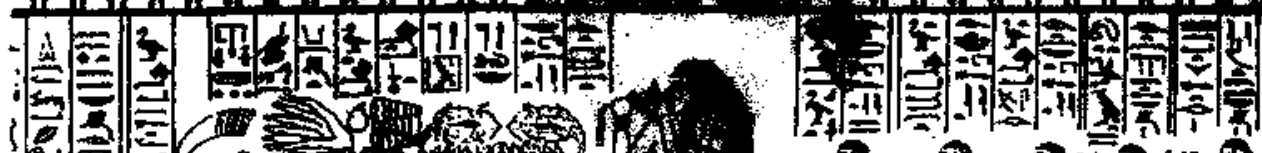

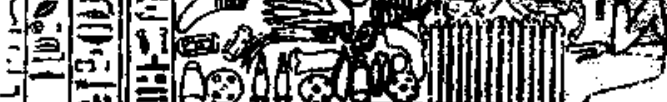

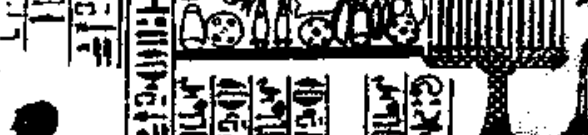

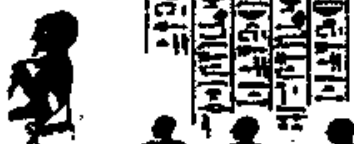

13:

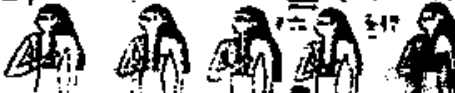

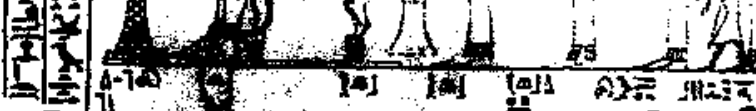
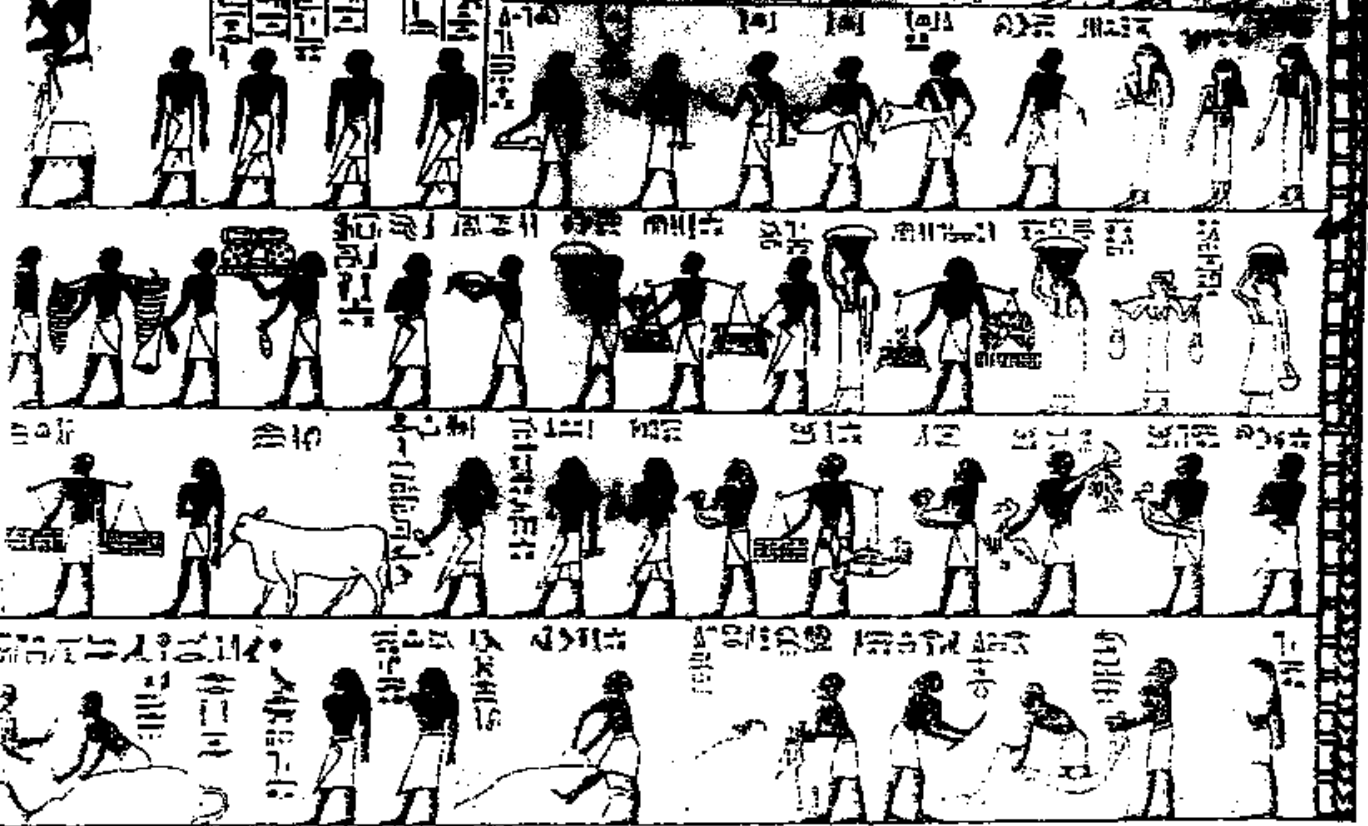

شكل ه- لإنط الجنويى من الحجرة اللرئيسية- مقبزة خنوم حتب الثانى (رقمب)

(Newberry, BH, l, pl , $35:$ : $)$ 


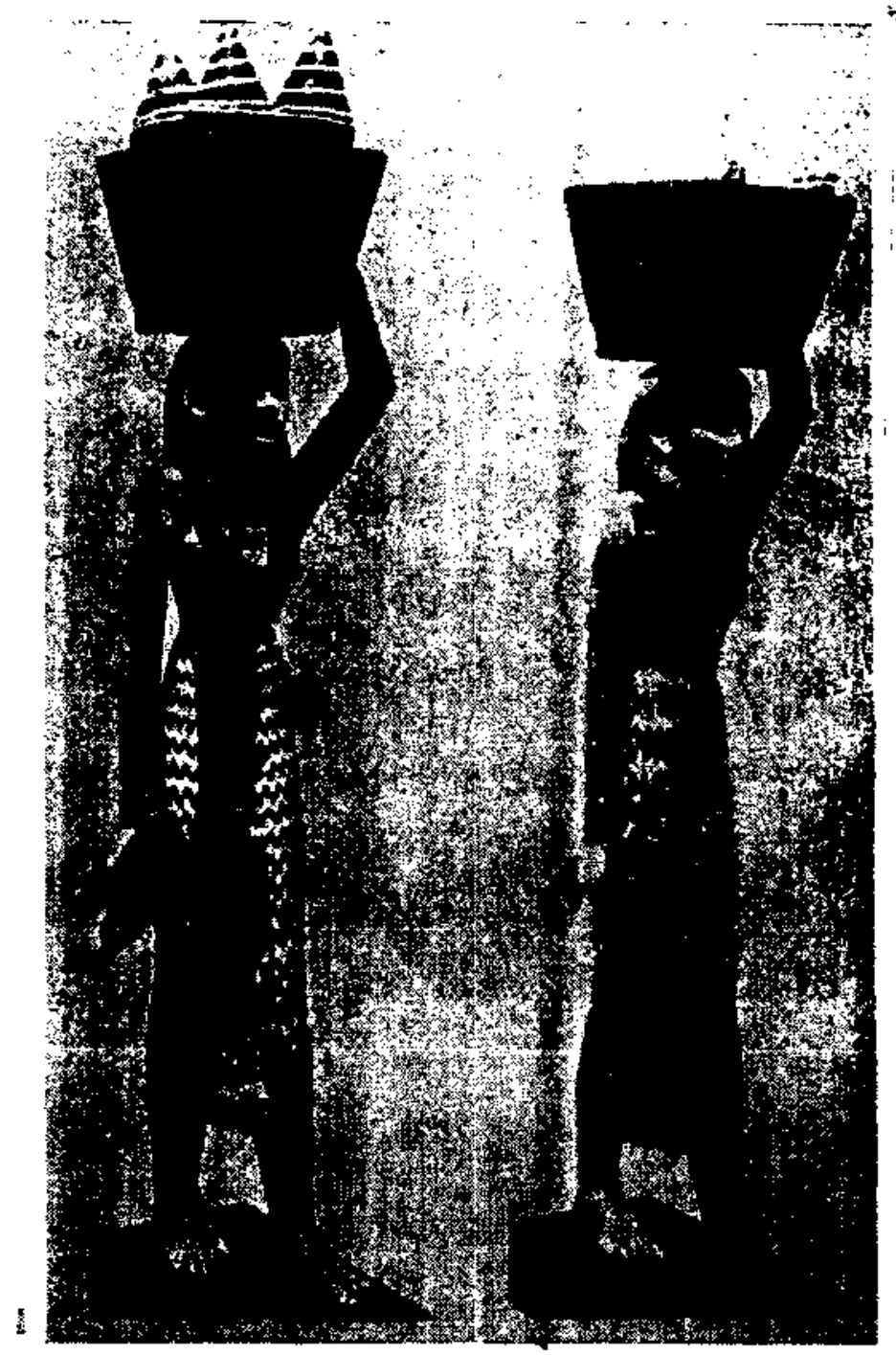

شكل آ- نموذجان لخادمتين تحملان مُر ابين (يظهران رشاقة الوصيفات)

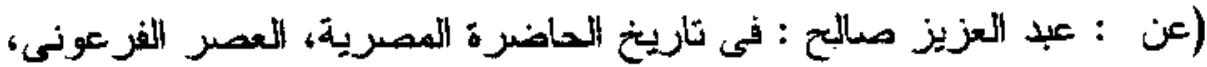

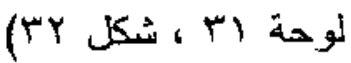

